\title{
A second Cretaceous ornithuromorph bird from the Changma Basin, Gansu Province, northwestern China
}

\author{
Hai-Lu You, Jessie Atterholt, Jingmai K. O’Connor, Jerald D. Harris, Matthew C. Lamanna, and Da-Qing \\ $\mathrm{Li}$
}

Acta Palaeontologica Polonica 55 (4), 2010: 617-625 doi: http://dx.doi.org/10.4202/app.2009.0095

Finely-bedded lacustrine deposits of the Aptian (Lower Cretaceous) Xiagou Formation exposed in the Changma Basin of Gansu Province, northwestern China, have yielded numerous fossil vertebrate remains, including approximately 100 avian specimens. Though the majority of these birds appear referable to the ornithuromorph Gansus yumenensis, a number of enantiornithine fossils have also been recovered. Here we report on a specimen consisting of a complete, three-dimensionally preserved sternum, furcula, and sternal ribs that represents a second ornithuromorph taxon from the Xiagou Formation at Changma. The fossil exhibits morphologies that distinguish it from all previously-known Xiagou birds and demonstrate that it represents a derived non-ornithurine member of Ornithuromorpha. Though it is morphologically distinct from the equivalent elements of all other described ornithuromorphs, the material is too incomplete to justify the erection of a new taxon. Nonetheless, it increases the taxonomic diversity of the Xiagou avifauna, thereby expanding our knowledge of Early Cretaceous avian diversity and evolution.

Key words: Aves, Ornithuromorpha, Aptian, Early Cretaceous, Gansu Province, China.

Hai-Lu You [youhailu@gmail.com], Institute of Geology, Chinese Academy of Geological Sciences, 26 Baiwanzhuang Road, Beijing 100037, PR China; Jessie Atterholt [ajes@berkeley.edu], Department of Integrative Biology, University of California at Berkeley, 1101 Valley Life Sciences Building, Berkeley, California 94720, USA (corresponding author); Jingmai K. O’Connor [jingmai@ usc.edu], The Dinosaur Institute, Natural History Museum of Los Angeles County, 900 Exposition Boulevard, Los Angeles, California 90007, USA and Institute of Vertebrate Paleontology and Paleoanthropology, Chinese Academy of Sciences, 142 Xizhimenwaidajie, Beijing 100044, PR China; Jerald D. Harris [jharris@ dixie.edu ], Department of Physical Sciences, Dixie State College, 225 South 700 East, St. George, Utah 84770, USA; Matthew C. Lamanna [lamannam@carnegiemnh.org], Section of Vertebrate Paleontology, Carnegie Museum of Natural History, 4400 Forbes Avenue, Pittsburgh, Pennsylvania 15213, USA; Da-Qing Li [daqingligs@gmail.com], Fossil Research and Development Center, Third 
Geology and Mineral Resources Exploration Academy, Gansu Provincial Bureau of Geo-Exploration and Mineral Development, 121 Langongping Street, Lanzhou, Gansu Province 730050, PR China.

This is an open-access article distributed under the terms of the Creative Commons

Attribution License (for details please see creativecommons.org), which permits unrestricted use, distribution, and reproduction in any medium, provided the original author and source are credited.

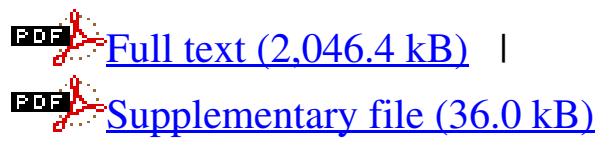

